\title{
Virtual Classroom and Traditional Classroom
}

\author{
Yan Sufeng \\ College of Foreign Languages, SJZUE \\ Shijiazhuang, China \\ Yansufeng242@yahoo.com.cn
}

\author{
Song Runjuan \\ College of Foreign Languages, HTU \\ Shijiazhuang, China
}

\begin{abstract}
The development of IT technology and the internet is important for the development of education technology. Virtual classroom is prevailing now. I analyzed carefully the differences between virtual classroom and the traditional classroom. The result is that traditional classroom is more suitable for our education and the virtual classroom is a proper complementarity. It is not reasonable to replace the traditional classroom with the virtual classroom.
\end{abstract}

Keywords- traditional classroom; virtual classroom; differences; replacement

\section{INTRODUCTION}

Virtual classroom refers to courses offered via the internet. It is a teaching and learning environment located within a computer mediated communication system. It consists of a set of group communication and work spaces and facilities that can surpass that of the traditional classroom, a process in which students and instructors are actively involved in creating and carrying out learning activities together like group discussion, joint projects, and debates, sharing of solutions to homework problems by emails, bulletin boards, chat rooms and conferences. The development of IT technology and the internet is the basis of virtual classroom [1]. Thus the virtual classroom possesses some of the characteristics of the internet which is what the traditional classroom does not have. For example, there is no limit of time, place, distance, and it is more convenient for both the students and the teachers to get more information from the internet [2]. It seems that this is hope for both teachers and learners to overcome all the problems existing in the traditional cleanroom and many people even are trying to use as much as virtual technology as possible in the real campus. They ignore the differences between virtual classroom and the traditional classroom. it also has its weaknesses which make it impossible to replace the traditional classroom education, especially in traditional college. And for some people, they really should think about the reason why they use this technology.

\section{THE BEGINNING OF VIRTUAL CLASSROOM}

The prototype of of virtual classroom is the computer conference. It was first adopted in certain fields in order to communicate and avoid the long journey. Then its application extends rapidly.

Firstly, the internet provides an interaction between human and the virtual world. People can decide what they want to do and what they want to say. They can find out almost all kinds of information they need on the internet.
And there is no concern about your appearance, gender, age, race, job or any barrier which may block real life communication [3].

Secondly, the educational theory is developing too. The educators come to an agreement that the traditional classroom is not good because it is teacher-centered and it should be learner-centered. Only in this way, the learners can develop fully and healthily [4]. The internet is just good enough to provide the opportunity for the learners to get to the center of learning. They can learn through the internet according to their own plan which is based on their own ability with the guidance of the instructors.

Thirdly, the virtual classroom is effective to ensure education equality, especially for those who are poor, or live in a remote area, or do not have regular time to attend school education. If they have access to the internet, the virtual classroom will provide them with the best teachers and the same courses with other learners. Thus, education equality is ensured.

Thus, this newly adopted method seems to solve a lot of problems which are almost impossible to be solved, at least in the near future it seems so, in the traditional classroom. All these are right. But we should never forget our real situation.

\section{THE ADVANTAGES OF VIRTUAL CLASSROOM}

The virtual classroom does have its own merits over the traditional classroom. The following is the well accepted advantages of virtual classroom

\section{A. A good way to develop students self-learning ability.}

The students in virtual classroom have to learn how to begin their learning, how fast they can go, how to solve some of the problems by themselves. These are really helpful to develop their learning ability. And the students become the main body of learning process. They can learn faster if they can. It is good for individual development. And if they foster the self-learning ability in the virtual classroom, they will benefit from it for all their life.

\section{B. It encourages inquiry learning.}

Inquiry learning refers to the learning process through which the students learn knowledge by exploring the question. This learning method focuses on the students' automatic choice of projects, self-exploration and free creation. In the virtual classroom, the students choose their own questions. Then collect data and try to solve the problem all by them. They learn a lot during this process and 
they grab the method of solving problems and obtain knowledge. They also can improve their ability to be creative.

\section{It is more open.}

That is one of the biggest advantages of virtual classroom. Students can regester a course without the limitation of time, place, age and other factors. You can learn in the morning, afternoon,or at night if only you have the time because the internet is in service 24 hours aday and 7days a week. You can work while you attending the virtual calssroom and learn whatever you like. It is cheaper. You can save your boarding fees, cost to travel to-and-from the campus.

D. It is especially good for introversivet language learners.

This is well accepted that the virtual environment is beneficial for the introversive learners. They are too shy to speak out facing so many students. If they attend virtual classrooms, they are facing the computer, so they will not feel intimidated. They can talk loudly to the computer. No one will laugh at them when they make mistakes. The computer recording software will record their voices and replay them to the learners. That is really a good way to improve one's oral English. What's more, the students can have more time to think about the answers to a question. They will be well prepared. Thus, their confidence in learning will be promoted.

\section{THE DIFFERENCES}

\section{E. The teaching environment is completely differenct.}

The traditional classroom has its own campus and fixed classrooms. Students wither live near the college or on the campus. They attend class every day and follow the same curriculum, while the virtual classroom is on the opposite. There are no limits of classroom, time schedule, or place. Students from all over the world can choose the same teacher and the same course. Most importantly, students who attend virtual classroom are not "pure" students. Unlike the full time students on campus, who are students and needn't worry about other things like work, family or duty, the students attending virtual classroom are mostly those who cannot attend the regular classroom. They have to worry about their life, work, or something else. So, it is more difficult for them than those regular students. At the same time, virtual classroom does not mean less effort or time. It is still time-consuming and energy-consuming if they want to learn better. They even need more efforts.

\section{F. There is great difference between students}

In the traditional classroom, the students are of the same age. Thus, the educator can make plans according to their psychological characters. The students are arranged into different classes. In the virtual classrooms, students are highly diversified, their age, life experiences, work experiences are all different. Thus, the teachers cannot assume the characteristics of their students.

\section{G. The time schedules are different.}

The traditional classroom goes according to a definite time table and has the same textbook. They plan courses according to the characteristics of the course and the cognitive development of the students. The students can learn different subjects in one day. It is more efficient. This is impossible for virtual classrooms students. They may not have so much time to learn different courses in a short time. They have to adjust their courses according to their time.

\section{H. Different ways of interaction.}

In the traditional classroom, teachers and students are the two participators of education. The teachers teach and the learners learn under the guidance of the teachers. The teachers need to lead the students to think and find out ways to solve problems according to the performance of individual students. They interact face to face. In the virtual classroom, they have to communicate through the internet. The face-toface communication is very rear, though it is possible due to the development of multimedia. When there is a face-to-face communication on the internet, it is only between the teacher and the one student. Other students are difficult to participate.

\section{THE TRADITIONAL CLASSROOM}

This way of teaching and learning has lasted for a long history. It is changing all the time. All advancement in technology will result in the change of teaching methods, even the teaching theory. The appearance of the internet is sure to change the teaching and the learning [5]. I believe it is not the time to replace the traditional classroom with the virtual classroom. Or our education should stress more about the virtual classroom. There are four reasons.

First, Chinese students are not familiar with this way of learning. They do not always decide what they want to do or what they should do due to the educational system. Thus, when they come to the college, they are used to be led by the teacher instead of manage their own study. That is the real situation. Their life and learning before college are arranged [6]. They have no say about their study. As a college teacher, I always meet students who ask me to tell them what they should write down. If I do not tell them, they do not know what is important. Many students just like to listen to the teacher. They seldom think by themselves. They do not know what they like or dislike. They just want to learn what they should learn, which is what the teachers or the parents say. Thus, teachers need a lot of energy and time to help students to learn how to manage their own work and time. If the teachers just let them to choose or decide what they can do next, they will be lost. They will think this teacher is really not good.

Second, for colleges, there are enough teachers, enough classrooms. It is not necessary to bother to use the virtual classroom. The real-life face-to-face teaching and learning is more effective. The virtual classroom was first design to help those who are not convenient to come to the classroom or for those who are no schools to attend [7]. Since this is the college, why should we do so much for the regular students? They come to the university; they take part in all the 
activities; they could afford the tuitions. Then, we say students should take some virtual courses for their own sake. I really do not see there is the necessity to do so.

Thirdly, the virtual classroom is more demanding for both the teachers and the learners. Teacher must learn their specialty well. At the same time, they must know how to use the software. They have to arrange time for virtual conference, answer students' questions, design interesting materials, and evaluate the students without actually seeing them. The student attending the virtual classroom must get on the internet. As we all know, there are more interesting things on the internet than the course work. They must control them. If they can make good use of the searching engines, it seems possible that all the questions they need to answer may be simply done by searching the internet for the answers. Do do not collect materials. They do not do research, they search for the answers. That is obviously easier than doing research. There are correct information and wrong information. They may be misled.

Finally, the teachers' demonstration is too important to be dismissed. In the traditional classroom, the teachers and the students can interact. Students can learn a lot from teachers' expressions, smile, or gesture [8]. The teachers also can alter their strategies according to the reaction of the students. For the virtual classroom, this is almost impossible. Thus, their education is not complete. A smile may be a great encourage for students. The students attending the virtual classroom will mainly focus on their own thoughts and the questions they're dealing with. There is less interaction with others. Thus, if the students focus on virtual classroom or the internet too much, they will lose their ability to deal with real people in reality. That is the biggest side effect of virtual classroom. In addition, there are more interesting materials on the internet. Students may be distracted by that information. If the students lack the ability to tell the fake information from the true information, they are easy to be misled.

\section{CONCLUSION}

All in all, the traditional classroom should still be the main force of education today. The virtual classroom is a good complementarity of the traditional classroom. It at least provides some people with the opportunity to education. Thus, I believe the combination of the two methods will be better suiting our education.

However, there are still problems waiting to be solved, such as the proportion of the virtual classroom and the traditional problem. Educators should employ different methods for different students. But, the virtual classroom really and some advantages which overcomes some of the traditional classroom disadvantages. Thus, some educators believe apply virtual courses to the traditional classroom is also practical. And there are evidence to show that American regular students also attend virtual courses. Thus educators should think more about what kind of courses are suitable for virtual learning and what courses are better taught in traditional classroom. The materials and curriculum and textbook for virtual courses should be specially designed too.

\section{REFERENCES}

[1] A. E. Weiss, Virtual reality. Twenty-first Century Books. 1996.

[2] W. Xinhua. Teaching and learning in the virtual classroom . Foreign language education. 2006. Pp258-262.

[3] W. Heyuan, on instructional characeristics and methods in the birtual class. Modern college education. 2003, vol3. Pp 85-87

[4] L. Quyuan. Teaching theory and methods in higher education. Changcha: Hunan education press. 1990, pp,132-133.

[5] M. Zhiguo. An analysis of the origin of virtual education. Journal of Liaoning teachers university. 2006. Vol29 pp 60-63

[6] Z. Lixin. Two worlds, two classrooms. China educational technology . 2009, Pp 7-9

[7] H. Xiaowen, Reflections on the virtual classroom. Journal of Ningbo TV college. 2008.Pp 85-87.

[8] L. Zhidong, Teaching theories and strategies of virtual classroom. Jignsu educational research. 2011. Pp 53-54 